\title{
El contrato
}

\section{llave en mano*}

/ Turnkey

Contract

* Osorno Sánchez, Armando, El contrato llave en mano (Turnkey Contract), México, BUAP, 2012, 413 pp.

Tla-Melaua, Revista de Ciencias Sociales. Facultad de Derecho y Ciencias Sociales. Benemérita Universidad Autónoma de Puebla, México / IssN: 1870-6916 / Nueva Época, Año 7 No 34, Abril - Septiembre 2013, pp. 192-195. 
La globalización se puede definir como un proceso dinámico de simultaneidad y de creciente libertad e integración mundial de los mercados de trabajo, bienes, servicios, tecnología y capitales. Dicho proceso está basado en una serie de libertades: la libertad de comerciar con el resto de los países del mundo aprovechando las ventajas comparativas de cada uno; la libertad de invertir los capitales allí donde tienen un mayor rendimiento con un riesgo asumible y la libertad de establecerse en el país que se desee, bien para conseguir un mayor beneficio o una mayor cuota de mercado, si se trata de una empresa, o bien para obtener un mayor salario o mejores condiciones de trabajo, si se trata de una persona (migraciones), etc.

Este fenómeno de simultaneidad mundial, que caracteriza a la situación global como sociedad informacional, se realiza en un proceso de desregulación de los controles centrales de las economías y de las formas institucionales y de organización social de los Estados y sociedades nacionales, creando un proceso de fragmentación y de ruptura interna entre ellas. ${ }^{1}$

En este orden de ideas, podemos señalar como principales características de la globalización las siguientes:

a) La globalización de la economía, representada por la interdependencia entre las economías nacionales, las industrias, las empresas y los bloques regionales.

b) El incremento en el comercio internacional y la gradual eliminación de barreras al mismo, lo cual permite la vinculación más estrecha y cercana entre países, las industrias y las empresas, haciendo del mundo un mercado global.

c) Incorporación de nuevas tecnologías. Mediante la globalización se permite la introducción de cambios esenciales en los métodos de producción. Los avances recientes en el área de telecomunicaciones han facilitado la integración de los mercados nacionales.

d) Movilidad de capitales e inversión extranjera directa, conformando una economía mundo.

En materia económica, las personas físicas y jurídicas, además del Estado, en términos generales, son los que actúan como agentes económicos en la producción, distribución y consumo de bienes físicos transportables y

\footnotetext{
** Investigador titular "C" tiempo completo en el Instituto de Investigaciones Jurídicas de la UNAM, México. (witker@unam.mx)

'Pozas Horcasitas, Ricardo, "La Integración Global", en Valero, Ricardo (coordinador), Globalidad: Una mirada alternativa, México, Centro Latinoamericano de la Globalidad, Miguel Ángel Porrúa,1999, 256 pp.
} 
servicios o intangibles. No obstante, como resultado de las tendencias globalizadoras, dichos sujetos se han ido modificando y han hecho partícipes sobre todo a las grandes empresas privadas transnacionales o multinacionales (Consenso de Washington), disminuyendo la participación del Estado como agente y regulador económico.

En los niveles conceptuales se ha intentado hacer sinónimos los conceptos de globalización y posmodernidad, los cuales visualizan a los Estados nacionales desde perspectivas relativamente semejantes. En efecto, la modernidad se basa en la idea de Estados-Naciones fincados en territorio, población y gobierno, conceptos que han sido sustituidos por espacios globalizados e integrados, allende los confines del territorio de la Nación-Estado.

Por su parte, la posmodernidad que alienta la inmediatez consumista, de corto plazo, sin perspectivas ni lealtades a países o regiones, encuentra en la globalidad empresarial un referente adecuado para abatir y erosionar las instituciones estatales y sus indispensables políticas públicas. Así, desde esta perspectiva, globalidad y posmodernidad son vertientes que convergen en la cultura de los mercados actuales, que suplantan a los Estados-Nación, llevando a las sociedades contemporáneas a extremos asimétricos, concentrados y excluyentes: las economías locales y emergentes.

$\mathrm{Al}$ intentar trasladar los ejes motrices de la actividad económica, de lo público a lo privado, tres fenómenos se presentan a la percepción y acción de los agentes económicos:

a) La extraterritorialidad o desterritorialización de las relaciones jurídicas, derivada de multifuentes que provocan la interacción empresarial global, por ejemplo, propiedad intelectual, arbitrajes privados, derechos ambientales, etc.

b) El fenómeno de la simultaneidad que, derivado de la globalidad electrónica, conjunta las categorías tiempo y espacio en donde Internet, el comercio electrónico y demás vectores de la telemática crean derechos y obligaciones a distancia que el derecho moderno no alcanza a registrar.

c) El pensamiento complejo, que incorpora elementos que hacen que las categorías jurídicas tradicionalesentren en disfunciones o desuso. Nuevas figuras emergen al mundo mercantil empresarial: el contrato llave en mano, los contratos intangibles y los nuevos mecanismos de solución de controversias evidencian la noción de un derecho de softlaw que privilegia la negociación por sobre la sanción o penalidades (hardlaw). Estos fenómenos condicionan nuevas realidades y exigencias que invitan a la generación de nuevos conocimientos jurídicos y, al mismo tiempo, a inéditas soluciones pragmáticas para tales procesos.

Para atender y registrar tales escenarios, nuevas categorías y convenciones jurídicas han surgido en la arena de los negocios globales. La complejidad 
como categoría que rompe esquemas conceptuales clásicos emerge al mundo de la globalización jurídica.

Así, los contratos son impactados por realidades jurídicas inéditas, en donde los objetos de los mismos son polivalentes ya que recaen sobre tangibles e intangibles, derivando de ellos relaciones jurídicas desconocidas que convergen en obligaciones de dar y de hacer, en forma casi simultánea.

En efecto, los paradigmas contractuales clásicos, como la autonomía de la voluntad, la libertad contractual y la propia igualdad, han cedido importancia ante las concentraciones y fusiones de capitales que la gran empresa impone globalmente más allá de los llamados órdenes públicos económicos estatales.

Así surgen los contratos llave en mano (turnkey contract), que en nuestro derecho interno se relacionan, en parte, con los conocidos y polémicos contratos de servicios múltiples, últimamente llamados contratos incentivados, fronterizos a los contratos de desempeño, de extendida utilización en el ámbito energético mundial.

A describir y analizar el contrato llave en mano está destinado el texto del doctor Armando Osorno Sánchez, quien evidencia una erudición a todas luces excepcional y abordael particular en cinco capítulos, escritos en un lenguaje técnico, claro y preciso.

El método comparado y analítico que integra este importante libro permite captar una información dispersa y escasa, que indudablemente coadyuvará a los estudiosos y practicantes jurídicos a familiarizarse con estos contratos que los mercados globales están exigiendo cada día más al mundo profesional del derecho.

Con agrado y satisfacción presento estas líneas a título de recensión, a este innegable esfuerzo académico del doctor Osorno Sánchez, esperando que sus logros académicos sean reconocidos y evaluados, especialmente por la comunidad jurídica de la Benemérita Universidad Autónoma de Puebla y por el Foro Nacional de los Profesionales del Derecho. 